\title{
An effective way to rock mass preparation on metallic and nonmetallic quarries Ukraine
}

\author{
Kostiantyn Ishchenko ${ }^{1, *}$, Volodymyr Konoval $^{2}$, and Liudmyla Lohvyna ${ }^{1}$ \\ ${ }^{1}$ Institute of Geotechnical Mechanics named by N. Poljakov of National Academy of Sciences of \\ Ukraine, 49005, Dnipro, Simferopolska Str., 2a, Ukraine \\ ${ }^{2}$ State Technological University, 18007, Cherkasy, Shevchenko Str., 152, Ukraine
}

\begin{abstract}
A method in experimental studies and industrial-polygon particular conditions justifying the choice of a rational design of an explosive charge. The comparative results of the evaluation of the stress wave's amplitudes studies and the character of crushing hard media from the explosion of the charge explosives-variable and constant cross section. The dependences of the particle size distribution of various designs explosive charges destroyed by the explosion are constructed. In industrial conditions, the rationale for the explosive boreholes location according to the massif structure. Adjusted boreholes location grid on rational parameters blasting unit, determined using a novel method of breaking rock complex structure. A new design of a combined borehole charge of variable cross section has been proposed. Industrial tests performed and evaluation of the effectiveness of the proposed method blasting locally fractured rocks and ore deposits on non-metallic minerals. Recommendations on their use are given.
\end{abstract}

\section{Introduction}

A significant portion of the energy expended in the blast zone immediately adjacent to the charging of the cavity (usually 2-3 charge radius), where the overgrinding environment, leading to losses of minerals on metallic and nonmetallic quarries.

As noted in [1], management of the size of the overgrinding zone of rocks and reduction of the fine fractions output can be achieved both by reducing the contact area of the boreholes charge and the rock to be destroyed, and by creating conditions that reduce the dynamic impact of an explosion on the charging cavity surface.

In this case, the useful effect of a rocks blasting can be enhanced in various ways, and in particular, by regulating the value of the specific energy of the explosive by a combined charge of variable cross section.

There are several ways to form elongated charges, such as: the creation of extended areas, the diameter of which is larger than the diameter of the original charging cavity, in the probing wells [1-3], placing inside the charging cavity of a continuous column of explosive in polyethylene shells of variable diameter [4], with an air gap and reflector of

${ }^{*}$ Corresponding author: ishenko_k@i.ua 
blast waves [5] in the form of a cone with a decreasing diameter to the wellhead [6], shaped charges [7], combined charges for the complex structure rocks blasting [8-9], charges with different cross section configurations [10-11], charging location within the cavities of hollow shapes of inert material [12].

The above construction of elongate borehole charges in the massif can create differently directed and different gradient stress field and simultaneously reduced, by reducing the area of direct contact with the rock dynamic of the explosion impact on the charging chamber surface.

The above design of elongated borehole charges in the massif can create a multidirectional and multigradient stress field, while reducing the area of direct contact with the rock during dynamic explosive effects on the charging chamber surface.

The aim of the research - study and the effectiveness evaluation of strong rocks destroying by variable section charges with cumulative effect.

\section{Experimental results}

\subsection{Method experimental studies fracture solid media with blast}

Blasting operations at mining enterprises largely determine the effectiveness of subsequent technological processes. One of the effective methods of controlling the explosion action, and, consequently, rocks crushing, is the correct choice of the explosive charge design. To estimate the wave and a destructive action of explosion in hard media by charges of different designs are elaborated a method of modeling rock explosive destruction [13].

The purpose of the experimental studies - justification, selection and evaluation of the destructive action of the new design of the charge voltages largest amplitude in the compression wave generated by the explosion of the same by weight explosive charges of different designs.

For experimental studies were made of the model of sand-cement mixture cubic shape with edge $150 \mathrm{~mm}$. In the center of the model was formed cylindrical cavity (diameter $10 \mathrm{~mm}$, depth $85 \mathrm{~mm}$ ) for placement of explosive charges. Around the charging chamber and adjusted in its end face 2 of the sensor, one to a depth of $75 \mathrm{~mm}$ from the upper face pattern and spaced from the axis of the charge of $45 \mathrm{~mm}$, and the other - at a distance of $20 \mathrm{~mm}$ below the end of the charge cavity (Fig. 1).

Ceramic sensors are quadrants disc diameter $14.8 \mathrm{~mm}$ and a thickness $65 \mathrm{~mm}$. Before installing the sensors in the model were measured their electrical capacity and is calculated discs area. The area of each sensor is equal to $1 / 4$ of the disc area and was $4.3 \cdot 10^{-5} \mathrm{~m}^{2}$. Then conducted calibration electric converters resonance-ant resonance method, and the piezoelectric modulus was determined by calculation each sensor [15].

In the charging cavities of the models, elongated cylindrical charges of various designs were formed: charges of constant cross section, variable cross section, with boiler expansion at the end; charge of variable diameter (charges with uniformly alternating along the charge column narrowed and widened sections; charges with an air gap and a spherical insert - a hollow ball inside the charge). Schemes study designs charges are shown in Figure 2.

Elongated charges were formed in paper cartridges, the outer diameter of which was 0.95 diameters of the charging cavity. Ammonite \#6 with a mass of $3.5 \mathrm{~g}$ was used as an explosive. For all series of experiments, the specific consumption was $0.3 \mathrm{~kg} / \mathrm{m}^{3}$. Charges initiated segment of detonating cord length of $0.8 \mathrm{~m}$, connected to a detonating cap and detonating device. Explosions models produced in a thick-walled metallic rubberized blasting chamber (Fig. 3). 


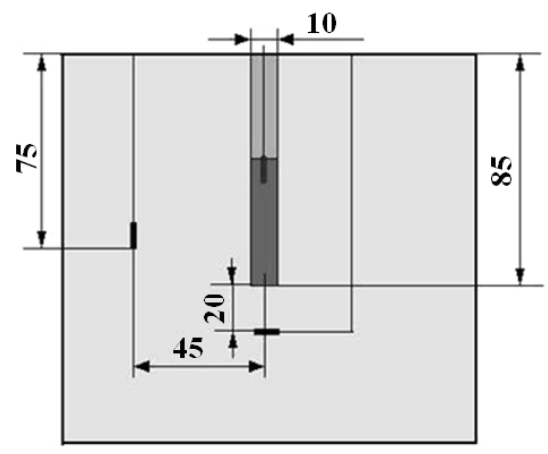

Fig. 1. The layout of the sensors in the model relative to the charge of explosive.

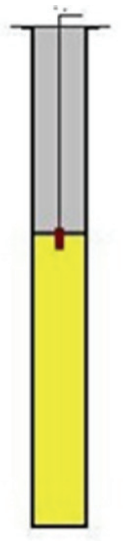

a

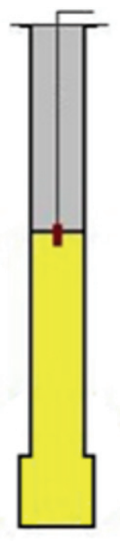

b

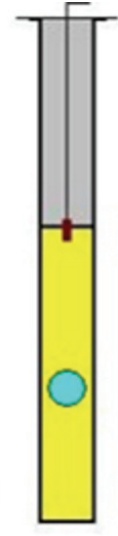

c

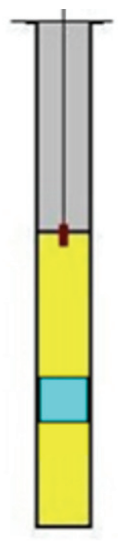

d

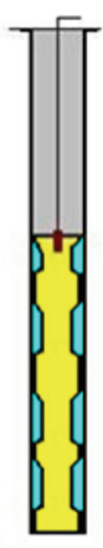

$\mathrm{e}$

Fig. 2. Charge construction: $a-$ constant cross section explosive charge; $b$ - charge explosive with boiler expansion at the end holes; $\mathrm{c}$ - explosive charge with a spherical insert; $\mathrm{d}$ - charge with an air gap; e - variable diameter explosive charge.

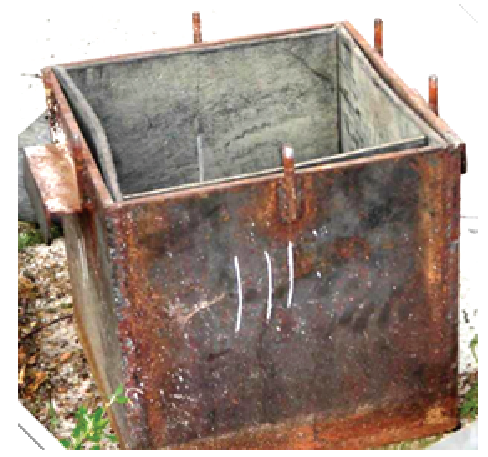

Fig. 3. Appearance of the blast chamber.

When charges exploded in the models, the maximum mechanical stresses in the compression wave were recorded by sensors and converted into electrical signals, which in the form of a code were fed to an digital oscilloscope.

Before the measurements were carried out oscilloscope calibration and set necessary for this experiment the sensitivity of the amplitude and duration of signals obtained during test explosions. 
Read and encoded information is transmitted to the computer system - NOTEBOOK, where is the use of special programs processed and displayed on a monitor in the dialog box as a waveform with numeric data on the entire measurement range. The oscillograms were used to determine the maximum values of the electrical signals and the pulse duration.

After the destruction of the explosion models, the crushing products were scattered on laboratory sieves with openings of $0.25 ; 0.5 ; 1.0 ; 2.0 ; 3.0 ; 5.0 ; 7.0 ; 10.0 ; 12.0 ; 16.0 ; 20.0$; $26.0 ; 30.0 ; 40.0 ; 50.0 ; 60.0 ; 70.0 ; 80.0 \mathrm{~mm}$ and established their main particle size characteristics [16].

\subsection{Results and discussion}

Experimental studies of the explosion wave and destructive various designs charges action on models were carried out in the conditions of PJSC Poltava mining and processing plant according to the developed technique [15]. The experimental data were calculated stresses in the compression wave at the same distance from the axis of the charge.

The distance from the charging cavity to the sensor for various designs of the explosive charge was $9 r_{0}$ in the horizontal direction and $4 r_{0}$ vertically, i.e. at the end of the charging cavity, ( $r_{0}-$ charging cavity radius).

The mechanical stresses $\sigma$ arising in the model during the explosion of an extended explosive charge, then converted by electrical piezoelectric sensors into electrical signals, were recorded with a digital oscilloscope and calculated by the formula

$$
\sigma=C U /\left(d_{33} S_{\mathrm{seg}}\right)
$$

where $C$ - electric sensor capacitance, F; $d_{33}-$ piezomodulus, $\mathrm{C} / \mathrm{N} ; S_{\text {seg- }}$ sensor surface area, $\mathrm{m}^{2} ; U-$ a voltage, $\mathrm{V}$.

In processing the particle size distribution was determined: total mass destroyed by explosion of the model, the content of fine fraction, the content of coarse fractions and the average diameter of the piece. The results of analysis of experimental data given in Table 1.

Table 1. Calculated and experimental data from the explosion of various designs charges in the model.

\begin{tabular}{|c|c|c|c|c|c|}
\hline \multirow{2}{*}{$\begin{array}{l}\text { Explosive charge } \\
\text { constructions }\end{array}$} & \multicolumn{2}{|c|}{$\begin{array}{c}\text { Stresses in the compression } \\
\text { wave, } \sigma, \mathrm{GPa}\end{array}$} & \multirow{2}{*}{$\begin{array}{c}\text { Mass } \\
\text { explosion } \\
\text { destruction } \\
\text { of the } \\
\text { model, g }\end{array}$} & \multirow{2}{*}{$\begin{array}{c}\text { Content of } \\
\text { large } \\
\text { fractions } \\
d_{i}>50 \mathrm{~mm}\end{array}$} & \multirow{2}{*}{$\begin{array}{c}\text { The } \\
\text { middle } \\
\text { piece } \\
\text { diameter } \\
d_{m}, \mathrm{~cm}\end{array}$} \\
\hline & $\begin{array}{c}\perp \text { to the } \\
\text { compression } \\
\text { wave direction }\end{array}$ & $\begin{array}{l}\text { At the end } \\
\text { of the } \\
\text { charge axis }\end{array}$ & & & \\
\hline Constant section & 0.010 & 0.025 & 2470 & 1020 & 30.7 \\
\hline Air gap & 0.0098 & 0,025 & 3760 & 1330 & 33.0 \\
\hline Spherical insert & 0.012 & 0.033 & 3480 & 1630 & 35.0 \\
\hline $\begin{array}{l}\text { Sprung expansion in } \\
\text { the bottom }\end{array}$ & 0.0095 & 0.028 & 2600 & 1340 & 35.8 \\
\hline $\begin{array}{l}\text { Alternating narrowed } \\
\text { and widened areas }\end{array}$ & 0.008 & 0.000148 & 1980 & 850 & 32.5 \\
\hline
\end{tabular}

According to the particle size distribution of the destruction products of models by explosion of different designs charges, the histogram of crush fractions was built (Fig. 4).

Analysis showed the following results of experiments. During the explosion charges of variable in height section of the stresses in the compression wave are higher, the total mass 
of the models parts repulsed is greater than during the of other designs charges explosion, namely: constant section, variable diameter across the charge column, with the boiler expansion at the end and with air by the gap. In addition, increases volume as large fractions $d_{i}>50 \mathrm{~mm}$, and the middle piece diameter.

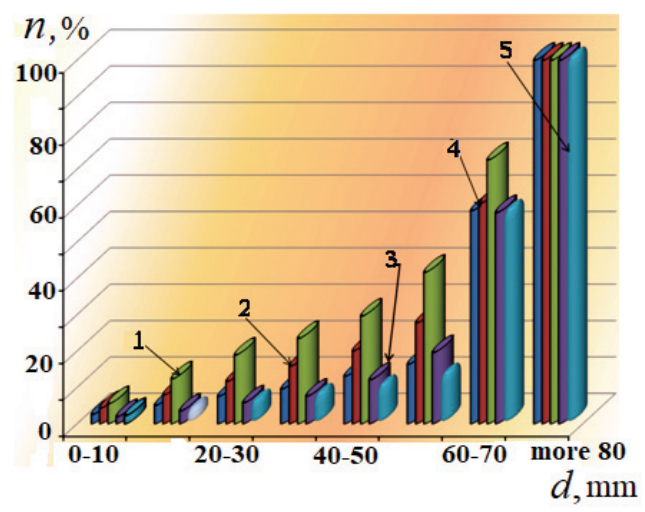

Fig. 4. Histogram of the models particle size distribution that destroyed by various designs explosive charges: 1 - charge with a spherical insert; 2 - charge with air gap; 3 - charge with boiler expansion at the hole end; 4 - total charge; 5 - variable diameter charge in column height.

\section{Experiment results in industrial conditions}

For rational justification parameters explosive fracture rocks complex structure (granite) quarries "Sivach", "Vita Soris", "Tomashhorod", "Ukrahrovzryvprom" industrial tests were carried out a new method of breaking [14] based on the change in charge of design features.

Rocks in quarries are represented by gray water-rich fine-grained granites with red inclusions of $f=12-16$ points on a scale of prof. M.M. Protodyakonov. The running water level in the boreholes reaches 1.0-2.0 m with average the massif water content of 15-20\%.

The nature of the complex structure rocks destruction, as is known, is influenced by both their microstructure (microcracks orientation and the physical and mechanical properties anisotropy of rock-forming minerals) and the macro-structure of the massif (joints spatial position of different morphology that divides the exploding block).

Therefore, when choosing the parameters of drilling and blasting operations (specific explosives consumption, geometry of the boreholes grid location and the breaking direction), such that micro and macro structures features should be taken into account. This allows obtaining a uniform crushing of the rock at the lowest possible fine fractions.

To establish the main characteristics of the fracture structure of the granite massif within the mining allotment of the quarries "Sivach", "Vita Soris", "Tomashhorod" using the methodology described in [14], a stereo photographic survey of the bare faces was carried out on the horizons selected for industrial testing developed methods for blasting complex structural rocks (block 01/12, horizon $+58 \mathrm{~m}$ and block 04/11, horizon $+68 \mathrm{~m}$ ).

Decryption stereo pairs performed using standard computer programs. Visible in photographs horizontal and vertical macrocracks in this case depicted as a different thickness of lines, followed by projection onto the surveying rail to determine basic parameters of rock fracturing breakable block (Table 2).

To determine the effect of cracks in the explosive on the anisotropic massif destruction along the slaughter line are drilled and blasted holes (diameter $36-43 \mathrm{~mm}$, the depth of 1.0$1.5 \mathrm{~m}$, explosive - ammonite patron \#6). By the size of large $a$ and small axis funnels explosion $b$ axes and its orientation relative to the north-south-line, the coefficient of 
anisotropy was calculated from the expression $K=a / b$ which averaged 1.14 . Using the developed nomograms (Fig. 5) and taking into account the data of the anisotropy coefficient, the parameters of the holes grid of the current passport for drilling and blasting operations in the experimental section of the block were equal to $4.5 \times 5.5 \mathrm{~m}$ instead of $5 \times 5 \mathrm{~m}$. Its long side coincides with the maximum values direction of the energy the explosion flow vector in the destroyed massif $F_{\max }$.

Table 2. Average crack systems distribution parameters for quarries "Sivach" "VitaSoris" and "Tomashhorod".

\begin{tabular}{|l|c|c|c|c|c|}
\hline $\begin{array}{c}\text { Name of joints } \\
\text { (Cloos nomenclature) }\end{array}$ & $\begin{array}{c}\text { Coefficient } \\
\text { of jointing, } \\
1 / \mathrm{m}\end{array}$ & $\begin{array}{c}\text { Distances } \\
\text { between } \\
\text { joints } \\
\text { walls, } \\
\mathrm{mm}\end{array}$ & $\begin{array}{c}\text { Distance } \\
\text { between } \\
\text { separate } \\
\text { joints, } \mathrm{m}\end{array}$ & $\begin{array}{c}\text { Width of the } \\
\text { higher zone } \\
\text { jointing, } \\
\mathrm{m}\end{array}$ & $\begin{array}{c}\text { Distances } \\
\text { between } \\
\text { zones } \\
\text { centers, } \\
\mathrm{m}\end{array}$ \\
\hline$S$-joints (longitudinal) & $3-5$ & $0.01-0.15$ & $0.1-2.6$ & $40-60$ & $45-66$ \\
\hline$Q$-joints (transverse) & $1-3$ & $1.0-3.5$ & $1.0-5.8$ & $50-60$ & $60-75$ \\
\hline$L$-joints (horizontal) & $3-7$ & $0.05-0.15$ & $0.5-1.5$ & $\begin{array}{c}\text { higher } \\
\text { jointing zones } \\
\text { are absent }\end{array}$ & - \\
\hline
\end{tabular}
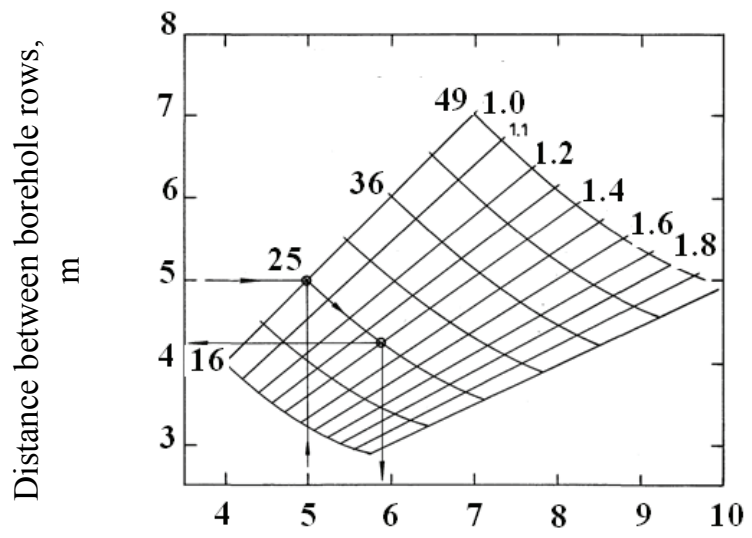

Distance between boreholes in the row, $\mathrm{m}$

Fig. 5. Nomograms for adjusting the boreholes grid with anisotropy coefficient.

In accordance with the modified parameters of the boreholes grid ( $a=5.5 \mathrm{~m}-$ the distance between the holes in the row and $b=4.5 \mathrm{~m}$ - the distance between the rows of wells), and also taking into account the zones of increased fracturing identified in one of the experimental blocks, oriented orthogonal face of the line, in the massif drilled boreholes according to the current passport blasting (diameter $150 \mathrm{~mm}$, depth 10.0-11.0 m, drill 0.6$1.0 \mathrm{~m}$ ). Scheme of the experimental block is shown in Figure 6.

After the blocks were drilled, holes were loaded (Fig. 8). Combined well charges were formed at the test area, according to the approved standardized passport for mass blasting for this block. To do this, the hole was left 2.0-2.4 m under the stemming, and the rest of the hole was divided into two equal sections. The mixed explosion of trinitrotoluene TNT (trinitrotoluene TNT + granulated ammonium nitrate in a proportion 65/35) or emulsion explosives such as Anemix were placed in the lower part of the borehole, the booster explosive of two TNT blocks T-400 connected by wave guide with plain detonator by non- 
electric system of initiation "Impuls" or "PRIMA-ERA" was installed. After that, the top part was filled with conversion explosive material (charge section is with plastid DKRP-4) and the top booster explosive was installed. The space between walls of borehole and section with conversion explosive was filled up with mixed explosive - TNT. The mouth of borehole was encapsulated by tamping of stone screening dust (fraction of 3-5 mm).

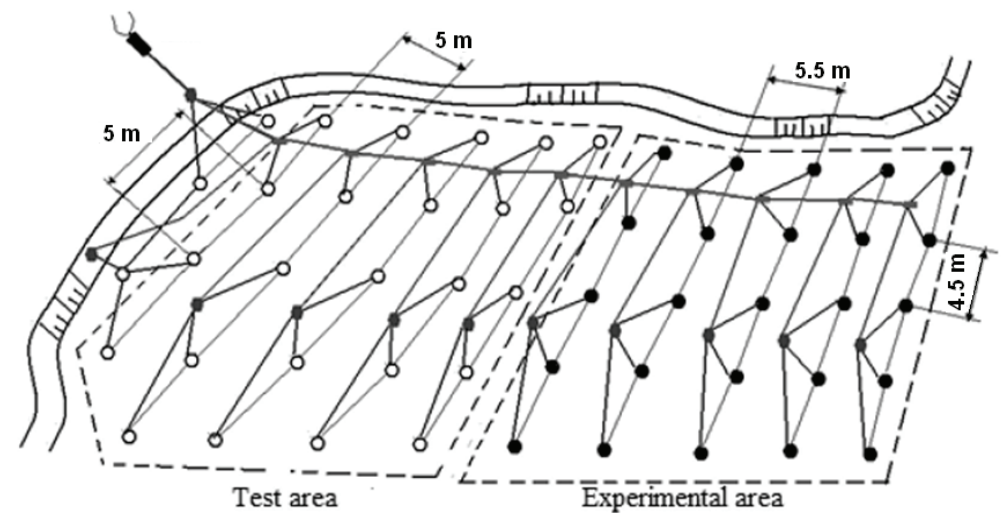

Fig. 6. The boreholes placement diagram and charges commutation (quarry "Sivach", block 01/12, horizon $+58.0 \mathrm{~m})$.

At the experimental site, the formation of charges was carried out taking into account the isolated zones increased fracturing. Thus, in the block rock mass in the direction of the extended zones with pronounced local fracturing in the drilled wells, extended combined charges of variable cross section were formed. The design of the developed variable-charge explosive of a variable cross-section is shown in Figure 7.

The formation of variable cross-section charges in holes was carried out by placing in the lower section of the explosives column, interconnected in a chain with a twine spherical cavities - balls, with a diameter of $0.8 D_{h}$ (Fig. 8), where $D_{h}$ - borehole diameter. The distance between the spherical cavities was taken equal to the active part of the shaped charge length [14].

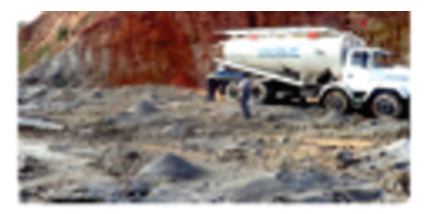

a
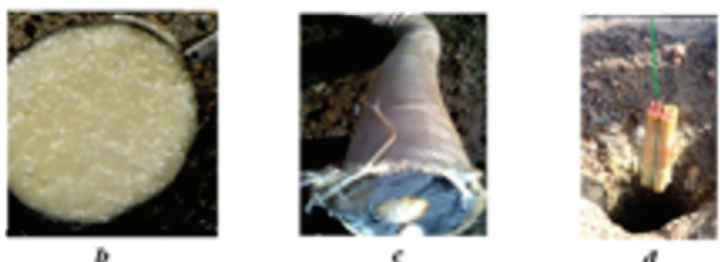

Fig. 7. Charge of boreholes on the block: $a$ - appearance of the unit with a charging machine; $b-$ emulsion explosive such as Anemix; $\mathrm{c}$ - charge section with conversion explosive; $\mathrm{d}$-installation of the initiator mounted from the TNT checker TN - 400 in the borehole.

Variable diameter charges of with spherical cavities are formed in monolithic block rocks zones, and continuous structure charges are formed in jointing zones. The lower section of charge was filled with the mixed explosion of TNT or emulsion explosive such 
as Anemix; the top section was filled with conversion explosive with plastid, and the top booster was installed. The space between walls of borehole and section with conversion explosive was filled up with mixed explosive - TNT or pyroxylin powder.

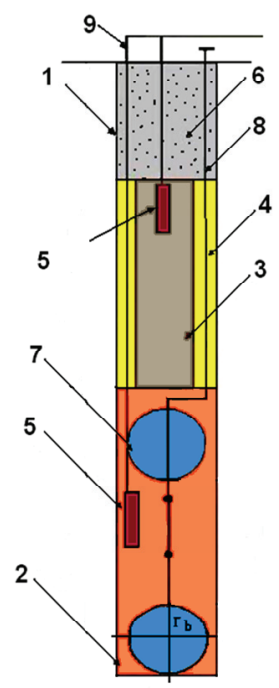

Fig. 8. Structure of the borehole multicharges variable diameter: 1 - borehole; 2 - mixed explosive charge; 3 - conversion explosive section; 4 - pyroxylin powder; 5 - primed blasting cartridge; 6 stemming; 7 - spherical cavities; 8 - binder for connection of spherical cavities; 9 - initiation "Impulse" non-electric system.

The charges groups were connecting in network carried out and then commutation of borehole charges on rock block took place. The delay elements of UNS-S and UNS-PA were placed between groups of charges in each level, and blasts were carried out starting with the charges located on the flank. Blasting on the block was proceeding with the use of non-electric systems of initiation "Impulse", NONEL, "PRIMA-ERA". According to results of mass explosions, the evaluation of crushing results of the blasted mined rocks was carried out in experimental and test areas. Quality of crushing was evaluated by diameter of an average piece with measurement of particle size distribution of blasted mined rocks with application of a method of oblique-angled photoplanimetry. The calculation results are presented in Table 3.

Table 3. Calculation of average piece sizes of blasted rocks mass on experimental explosions*.

\begin{tabular}{|c|c|c|c|c|c|c|c|}
\hline \multicolumn{4}{|c|}{ Experimental area } & \multicolumn{4}{|c|}{ Test area } \\
\hline $\begin{array}{c}\text { Fineness } \\
\text { classes, } \\
\mathrm{mm}\end{array}$ & $\begin{array}{c}\text { Average } \\
\text { size of } \\
\text { piece on } \\
\text { class, } \\
d_{i}, \mathrm{~mm}\end{array}$ & $\begin{array}{c}\text { Fractions } \\
\text { output, } \\
W_{i}, \%\end{array}$ & $d_{i} \times W_{i}$ & $\begin{array}{c}\text { Fineness } \\
\text { classes, } \\
\mathrm{mm}\end{array}$ & $\begin{array}{c}\text { Average } \\
\text { size of } \\
\text { piece on } \\
\text { class, } \\
d_{i}, \mathrm{~mm}\end{array}$ & $\begin{array}{c}\text { Fractions } \\
\text { output, } \\
W_{i}, \%\end{array}$ & $d_{i} \times W_{i}$ \\
\hline $0-200$ & 100 & 41.0 & 4100 & $0-200$ & 100 & 26.7 & 2670 \\
\hline $201-400$ & 300 & 34.0 & 10200 & $201-400$ & 300 & 24.5 & 7350 \\
\hline $401-600$ & 500 & 17.3 & 8650 & $401-600$ & 500 & 20.6 & 10300 \\
\hline$>600$ & 700 & 7.7 & 5390 & $>600$ & 700 & 28.2 & 19740 \\
\hline \multicolumn{3}{|c|}{$\Sigma$} & 28340 & \multicolumn{3}{|c|}{$\Sigma$} & 40060 \\
\hline \multicolumn{4}{|c|}{$d_{a v}=\sum d_{i} W_{i} / 100=283.4 \mathrm{~mm}$} & \multicolumn{4}{|c|}{$d_{a v}=\sum d_{i} W_{i} / 100=400.6 \mathrm{~mm}$} \\
\hline
\end{tabular}

Note: * - average values on experimental explosions. 


\section{Conclusions}

1. It has been established experimentally that with an explosion of a variable height charges, the stresses in a compression wave is higher than with an explosion of constant cross section charges. It is shown that the total mass of the model parts break by the explosion by a variable cross section charge is greater than with the explosion of other designs charges such as: of constant cross section, variable diameter along the charge column with the boiler extension on bottom and with an air gap. This increases the volume as large fractions $d_{i}>50 \mathrm{~mm}$ and the average diameter of the piece.

2. Analysis of the industrial experiments results showed that the use of modified parameters of drilling and blasting operations using designs of variable section charges (Table 2) reduces the average piece diameter by about $30 \%$ and the industrial explosives consumption by $10-40 \%$. The output of a standard piece $(201-600 \mathrm{~mm})$ is increased by $10 \%$.

3. A new method of blasting strong complex structural locally fractured rocks can improve the quality of the blasted rock mass crushing and improve the technical and economic performance of mining enterprises by adjusting the basic parameters of drilling and blasting.

4. The use of the proposed design of the combined borehole charge of variable crosssection makes it possible, with a constant mass of charge, to increase its length and, as a result, to more evenly distribute the explosives over the step height. At the same time, the conditions for the transfer of energy from the charge explosive change when a multigradient and multidirectional stress field is formed in the massif that collapses.

5. In the course of industrial tests in the period 2012-2018, according to the developed recommendations, about 1500 thousand $\mathrm{m}^{3}$ of rocks were blown up on granite quarries of PJSC "Ukrahrovzryvprom".

\section{References}

1. Efremov, E.I. (2007). Controlling the size of the over-grinding zone of rocks during their explosive destruction. Bulletin of the Kryvyi Rih Technical University, 18, 36-39

2. Osinnii, V.Ya., Osinnia, N.V. (2013). About the boiler cavity and the rational design of the charge at breaking of strong ores under underground conditions. Development, use and ecological safety of modern granular and emulsion explosives, 39-41

3. Osinnii, V.Ya. (2016). The penetration of the uprising excavations by blasting hole charges on the compensation cavity formed by the plasma method. Bulletin of the Ukrainian Union of Explosives Engineers, 1 (29), 17-20

4. Efremov, E.I. (2018). Destruction of solid media with their different gradient explosive loading by elongated charges of variable diameter. Collection of scientific works State $H E I$ "NMU”, 54, 52-60

5. Tyshchenko, S.V. (2015). Justification of the parameters of the downholes charge of an explosive with an air gap and a reflector from bulk materials. Metallurgical and Mining Industry, 2, 90-93

6. Rahmanov, R.A. (2013). Borehole charge designs with varying diameters at the top of the ledge. Gornyy informatsionno-analitichesriy bulletin, 8, 205-207

7. Norov, U.D. (2016). Intensification of the destruction of an array of various rock rocks with explosive charges with a cumulative effect. Mining Journal, 2, 32-34

8. Rahmanov, R.A. (2013). Substantiation of the parameters of the combined design of a downholes charge for a different massif. Gornyy informatsionno-analitichesriy bulletin, $8,207-209$ 
9. Dygarchirenov, A.V. (2015). Requirements for the choice of parameters for blasting operations for crushing complex rock massifs by combined and additional charges. Blasting work, 113 (70), 142-148

10. Petrenko, V.D., Konoval, S.V. (2014). Experimental investigation of influence of crosssectional shape of charge on nature of solid medium destruction, Suchasni resursoenergosberihaiuchi tekhnolohii hirnychoho vyrobnytstva [Modern resourcesaving technologies of mining production], 2, 31-43

11. Ishchenko, K.S. (2015). Features of destruction of solid media by explosive charges of various shapes. News of Higher Education. Mining Journal, 5, 75-79

12. Ishchenko, K.S., Kratkovsky, I.L., Konoval, S.V., Konoval, V.M. (2014). Method of blasting of local-fractured anisotropic rocks. Patent No 105730, Ukraine

13. Ishchenko, K.S., Konoval, S.V., Kratkovsky, I.L., Kruykovsky, V.V., Konoval, V.M. (2016). Method of simulation of explosive destruction of rocks. Patent No 110745 , Ukraine

14. Ishchenko, K.S. (2012). The way to create a heterogeneous explosive loading of a solid medium along the length of the charge, Suchasni resursoenergosberihaiuchi tekhnolohii hirnychoho vyrobnytstva [Modern resource-saving technologies of mining production], $2(10), 83-88$

15. Glozman, I.O. (1965). Piezoelectric materials in the electronic engineering. MoscowLeningrad: Energy

16. Baron, L.I. (1960). Lumpiness and its measurement methods. Moscow: Publisher AN USSR 